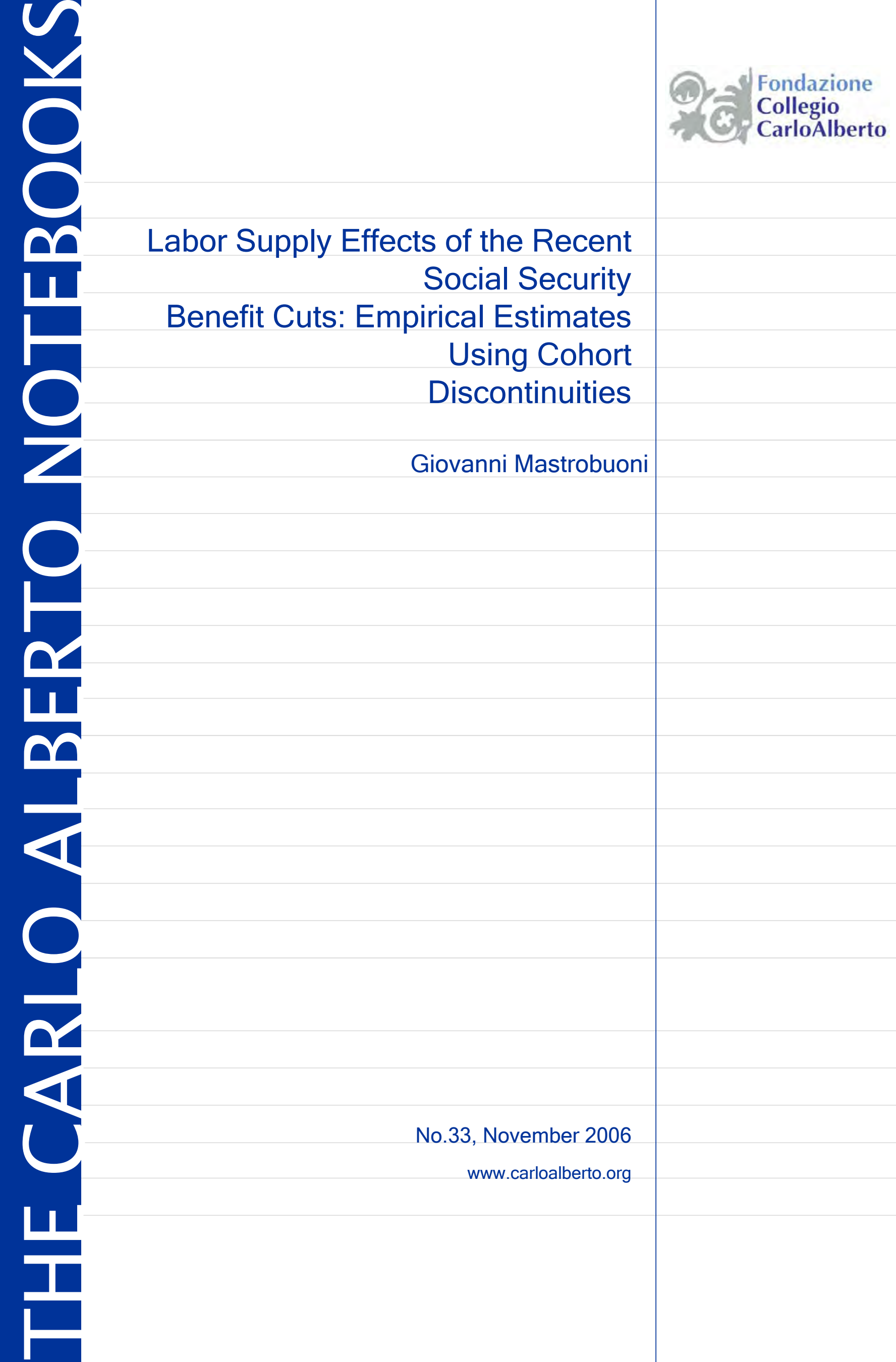




\title{
Labor Supply Effects of the Recent Social Security Benefit Cuts: Empirical Estimates Using Cohort Discontinuities *
}

\author{
Giovanni Mastrobuoni
}

June 2005, this version November $2006^{\dagger}$

${ }^{*}$ Collegio Carlo Alberto and CeRP, giovanni.mastrobuoni@collegiocarloalberto.it. I am particularly indebted to Orley Ashenfelter for his support. I would also like to thank Maristella Botticini, Wioletta Dziuda, Pietro Garibaldi, Bo Honoré, Alan Krueger, Franco Peracchi, Jon Vogel and all participants at the Princeton University Labor Seminar, and the 2006 EALE conference for their suggestions.

${ }^{\dagger}$ (C) 2006 by Giovanni Mastrobuoni. Any opinions expressed here are those of the author and not those of the Collegio Carlo Alberto. 


\begin{abstract}
In response to a "crisis" in Social Security financing two decades ago Congress implemented an increase in the Normal Retirement Age (NRA) of two months per year for cohorts born in 1938 and after. These cohorts began reaching retirement age in 2000. This paper studies the effects of these benefit cuts on recent retirement behavior. The evidence strongly suggests that the mean retirement age of the affected cohorts has increased by about half as much as the increase in the NRA. If older workers continue to increase their labor supply in the same way, there will be important implications for the estimates of Social Security trust fund exhaustion that have played such a major role in recent discussions of Social Security reform.
\end{abstract}

Keywords: normal retirement age, retirement behavior, social security reform JEL classification codes: H55, J26 


\section{Introduction}

In 1983, the U.S. Congress implemented an increase in the Normal Retirement Age (NRA) of two months per year. Each two-months increase in the NRA translates into a little more than a 1 percentage point reduction in Social Security benefits. This reform is likely to influence two important decisions that workers face at the end of their careers: (1) when to start collecting Social Security benefits, and (2) when to retire. Since benefits are adjusted actuarially with respect to the entitlement age, the long-term solvency of the Social Security trust fund depends more on retirement decisions than on claiming decisions. An increase in labor force participation generates more contributions, which are the trust fund's main source of revenue.

This paper studies the effects of an increase in the NRA on recent retirement behavior, providing the first ex-post evaluation of the reform. ${ }^{1}$ The evaluation yields both substantive evidence to inform future reforms and a guide to the calibration of structural models of retirement decisions. The results also raise serious questions about how best to improve the models on which earlier research was based. Using the change in the NRA to estimate the effect of Social Security incentives on labor supply provides additional benefits: the exact change in benefits is known, it is not prone to measurement error, and it is exogenous.

Due to the timing of the reform, workers born before 1938 are the control group and workers born in or after 1938, those who experience a reduction in benefits, are the treatment group. The analysis uses monthly Current Population Survey (CPS) data from January 1989 to January 2006.

Figure 1 shows the changes in average retirement age with respect to the 1937 cohort. Because of censoring, I focus on workers younger than 66, which leaves three treated

\footnotetext{
${ }^{1}$ Coile and Gruber (n.d.), Panis, Hurd, Loughran, Zissimopoulos, Haider and St.Clair (2002), Fields and Mitchell (1984), Gustman and Steinmeier (1985) use pre-reform data to simulate the effect of an increase in the NRA on labor supply.
} 
cohorts: 1938, 1939, and 1940. The dotted lines show piecewise-linear fits. In all plots there is a clear break in the trend toward later retirement between the 1937 and the 1938 birth year, and the break is even more evident when a restricted sample is used to correct for measurement error in the year of birth variable. ${ }^{2}$

The most obvious cause of this change is the increase in the NRA. Point estimates imply an increase in the actual age of retirement of about 50 percent of the increase in the NRA for both men and women. These results do not change when controlling for changes in socioeconomic characteristics.

Previous studies, using out-of-sample predictions, have estimated much smaller effects on labor force participation. Four major factors may have biased previous estimates, arguably toward zero. First, projections do not capture possible changes linked to norms that are related to the NRA. Evidence suggests that some workers look at the NRA as a focal point. Mastrobuoni (2006b) shows that the distribution of the age at which treated workers claim their Social Security benefits no longer spikes at age 65, but at the NRA.

Second, given that benefits are a function of past earnings, estimates based on these models may suffer from endogeneity bias. The third source of bias is that these models, since they are estimated using cross-sectional variation in Social Security benefits and retirement status, may capture long-term effects, while the 1983 benefit cuts may have been unexpected. Using a simple intertemporal model of retirement, I show that this can generate larger changes in the average retirement age than would otherwise be expected. ${ }^{3}$ The fourth problem is that in order to construct Social Security wealth, a component of all forward-looking incentives to retire, the researcher needs detailed information about past and future earnings, family structure (because of the dependent spouse and child benefits and the survivors benefits), interest rates, and preferences; in short, measurement error may be an issue. The increase in the NRA generates a reduction in Social Security wealth

\footnotetext{
${ }^{2}$ As first noted by Quinn (1999) the early retirement trend has reversed and is now decreasing.

${ }^{3}$ Benefit increases, instead, may generate smaller reductions in labor-supply when workers learn too late about them (Burtless 1986).
} 
that is exogenous and free of measurement error.

Despite the 1983 reform, the trust fund is projected to become insolvent in less than 40 years. While this date of insolvency is often portrayed by the news media as certain, it is only an estimate. One of the most important sources of uncertainty is the behavior of future workers and retirees. ${ }^{4}$ The NRA is scheduled to reach age 66 for the 1943 birth cohort, stay at that level for 12 years, and later resume the increase until it reaches age 67. To make better predictions, it is important to understand how these changes affect retirement behavior.

The paper is organized as follows. Section 2 introduces a simple intertemporal model of retirement. Its main purpose is to highlight that transitional effects arising from unexpected benefit cuts can generate large changes in the labor supply. Section 3 presents the empirical strategy. Section 4 shows that the estimated changes in retirement behavior are larger than previous out-of-sample predictions would suggest. Section 5 concludes the paper and Appendix A describes the data.

\section{A Simple Intertemporal Model of Retirement}

Life-cycle theory predicts that a worker's reaction to benefit cuts-a decrease in lifetime income-will depend on when one first learns about the reform. Attentive workers may have started reacting to the reform in 1983, and after 20 years of consumption-smoothing, the change in retirement behavior is likely to be small for them. Others may have learned about the increase in the NRA in 1995 when the SSA began mailing a Social Security Statement to all workers age 60 and over. The statement shows estimated benefits at different ages of retirement, including the first possible age of retirement and the NRA. Also, in 2000, the SSA added a special insert to the statement describing the changes in the NRA. The statements significantly improve workers' knowledge about their benefits

\footnotetext{
${ }^{4}$ See Anderson, Lee and Tuljapurkar (2003)
} 
(Mastrobuoni 2006a). In contrast, very distracted workers may not learn about the change in NRA until they claim their benefits.

The purpose of the model is to show that the reaction in terms of both consumption and retirement depends on the date at which the worker learns about the benefit cut. The model is standard; it assumes that workers maximize their utility over consumption $(C)$ and the time of retirement $(z)$. Retirement is an absorbing state, workers claim benefits at the time they retire and face a perfect capital market, with a rate of return $r$. There is no uncertainty about wages $W$ and mortality. The worker's problem takes the following form:

$$
\max _{z, C_{t}} V(z)=\int_{0}^{z} e^{-\delta t} U_{W}\left(C_{t}\right) d t+\int_{z}^{D} e^{-\delta t} U_{R}\left(C_{t}\right) d t
$$

s.t.

$$
\int_{0}^{D} e^{-r t} C_{t} d t=\int_{0}^{z} e^{-r t} W_{t} d t+\int_{z}^{D} e^{-r t} R(z, N R A, \mathbf{W}) d t
$$

where $D$ is the date of death, delta the discount rate, and $\mathbf{W}$ is the stream of earnings that enter the benefit formula. To obtain closed-form solutions, the utility function is assumed to be logarithmic. Disutility from work is captured by an additive constant $U_{W}=U_{R}-\epsilon$, where $U_{W}$ is a worker's utility level and $U_{R}$ is the worker's utility in retirement. In this setup, $e^{\epsilon}$ is the factor by which the worker's consumption must be increased to generate the same utility for the retiree. This disutility from work may additionally capture the observation that retirees tend to make better consumption choices (Aguiar and Hurst 2005) and that retirees do not have work-related costs. For simplicity the rate of preference equals the interest rate, $\delta=r$, and real wages are constant over time, $W_{t}=W$. The benefit formula used by the SSA expresses benefits as a function of past wages. Benefits increase with the difference between age of retirement and the NRA, 
$z-N R A$ :

$$
R(z, N R A, W)=R(W)(1+g(z-N R A)) .
$$

The policy variables are $g$, the actuarial adjustment factor, and the NRA. I focus on the NRA showing in Appendix B that this simple model generates two important predictions. First, for reasonable parameters, increasing the NRA delays retirement and reduces consumption. This result implicitly assumes that Social Security rules change at time zero. Second, for reasonable parameters, if rules change when the worker is already working, the response in terms of consumption and retirement is stronger. This occurs because an early-informed worker has more time to smooth consumption over time, and thus will not postpone retirement as much as a late-informed one.

\section{$3 \quad$ Empirical Strategy}

Figure 2 shows the cumulative distribution function (CDF) of retirement age by year of birth groups. The CDF for the treated cohorts is truncated at age 67, which corresponds to year 2005 for the first treated cohort (1938). Across all birth cohorts male workers exhibit very similar retirement patterns before age 62 . For female workers there is a clear trend toward later retirement at all ages.

The only age range for which the pattern of retirement of the treated cohorts differs systematically from that of the control group is $62-65$. At these ages treated workers (group 4), are more likely to be in the labor force than are untreated workers (groups 1, 2 and 3). Correcting for measurement error in the year of birth variable, this difference is even more pronounced (Figure 3).

These differences might, for example, depend on different educational attainments. In 
order to parametrically control for such confounding effects $(X)$, the distance between the CDFs of retirement age of different cohorts can be estimated by least squares using the following specification:

$$
y_{i}=\sum_{a=61}^{65} 1\left(A_{i}=a\right)\left(\alpha_{a}+\sum_{c \neq 1937} \beta_{a, c} 1\left(C_{i}^{*}=c\right)\right)+\gamma^{\prime} X_{i}+\epsilon_{i}
$$

where $y_{i}$ is equal to 1 when the worker is retired and zero otherwise. Retirement is defined as "out of the labor force", although results based on a more precise definition are almost identical. ${ }^{5}$ The indicator function $1\left(A_{i}=a\right)$ is equal to 1 if the worker is $a$ years old and 0 otherwise, and $1\left(C_{i}^{*}=c\right)$ is equal to 1 if the worker is born in year $c$ and 0 otherwise.

Since the specification includes all age dummies and omits the 1937 cohort dummy and the constant term, $\beta_{a, c}$ measures the difference at age $a$ between cohort $c$ 's and cohort 1937's CDF of retirement age, $\widehat{\beta}_{a, c}=E[Y \mid C=c, a, X]-E[Y \mid C=1937, a, X]$. Continuous $X \mathrm{~s}$ are not included in the regression, hence the linear probability model is completely general.

One limitation of the data is that the year of birth variable may be misclassified. ${ }^{6}$ CPS data contain information about the respondent's years of age at the time of the interview, but not the year of birth. ${ }^{7}$ Age at the time of the survey coupled with the information of the survey year and survey month provides, at best, an imperfect measure of the year of

\footnotetext{
${ }^{5}$ The more precise measure is only available after 1994, when the Bureau of Labor Statistics added retirement status to the labor force recode variable.

${ }^{6}$ Misclassification errors are not uncommon in empirical research. In a paper that analyzes the impact of the earnings test on labor supply, Gruber and Orszag (2003) take the most conservative approach of deleting observations for which ambiguity exists about the earnings test regime. Krueger and Pischke (1992) warn the reader that the probability of misclassification is approximately 20 percent when using the March CPS to establish the year of birth, but they do not explicitly correct for that.

${ }^{7} \mathrm{CPS}$ respondents provide their date of birth, though this information is later discarded from the public-use data. Unfortunately, because of the weak follow-up and the noisy identification of observations across waves, using the longitudinal component of the CPS allows me to get an exact measure of the year of birth for only a few observations. To match observations over time, I use the conservative approach of first matching by the CPS identifiers (hrhhid huhhnum hurespl), race and gender. After this first step, whenever the standard deviation of age is bigger than one-half, I additionally match by education, which for elderly people is normally constant over time (Madrian and Lefgren 1999).
} 
birth.

Months of birth are almost uniformly distributed (Table 1); as a result the probability of misclassifying the year of birth based on the survey month is known. If one simply generates the birth cohort as the difference between the survey year and age, in a January survey the probability of misclassifying someone's birth year is around $11 / 12$; someone surveyed in January is likely to have been born later in the year. The probability of misclassification is 10/12 in February, and, carrying out the calculation, zero in December. ${ }^{8}$ Using this method, the probability of misclassification would on average be one-half.

A better way to assign the birth year is to minimize the probability of misclassification. Adding a year to the cohort if the survey month falls in the first half of the year reduces the average probability of misclassification to one-quarter. I call this the "naive method." Additionally restricting the sample to the January and December surveys, the probability of misclassification is only $1 / 12$. I call this the "restricted method."

There is an obvious trade-off between minimizing the probability of misclassification and maximizing the statistical power. To avoid this trade-off and work with the whole sample I also use the "sophisticated method", which makes full use of the known probabilities of misclassification (Aigner 1973). The only empirical paper I am aware of that uses a similar approach is Card and Krueger (1992). Let $Y \in\{0,1\}$ be 1 if the worker is retired and define $C^{*}$ to be the true cohort and $C$ the observed cohort (equal to the difference between the survey year and age). The misclassification probabilities depend on the survey month $m, p(m)=\operatorname{Pr}\left(C^{*}=c-1 \mid C=c, m\right) . \operatorname{Pr}(Y=1 \mid C=c, m, a, X)=E[Y \mid C=$ $c, m, a, X]$ represents the conditional probability of having retired by age $a$, given that in month $m$ a worker is observed to be born in year $c$, while $E\left[Y \mid C^{*}=c, m, a, X\right]$ represents the probability of being retired given that a worker is truly born in year $c$. For ease of notation the other independent variables $X$ are omitted, but probabilities that are not

\footnotetext{
${ }^{8}$ To be more precise, given that the survey week always contains the 19 th of the month, the probability is (365-19)/365 in January and $11 / 365$ in December.
} 
misclassification probabilities are supposed to be conditional on $X$.

Assuming that given the true cohort, the mismeasured cohort is not informative, one finds that

$$
E\left[Y \mid C=c, C^{*}=c, m, a\right]=E\left[Y \mid C^{*}=c, m, a\right] .
$$

By the law of total probability,

$$
E[Y \mid C=c, m, a]=(1-p(m)) E\left[Y \mid C^{*}=c, m, a\right]+p(m) E\left[Y \mid C^{*}=c-1, m, a\right] .
$$

The probability of being retired depends on the survey month as well, since, conditional on a birth year (the true or the observed one), workers tend to be older later in the year. Assuming that conditional on cohort $C^{*}$, the dependence on the survey month is additively separable and does not change across cohorts, $E\left[Y \mid C^{*}=c, m, a\right]=E\left[Y \mid C^{*}=\right.$ $c, a]+g(m, a)$. Plugging this into equation (4), it follows that

$$
E[Y \mid C=c, m, a]=(1-p(m)) E\left[Y \mid C^{*}=c, a\right]+p(m) E\left[Y \mid C^{*}=c-1, a\right]+g(m, a)
$$

Averaging over the different survey months and defining $p=\sum_{m} p(m) \operatorname{Pr}(M=m)$ results in

$$
E[Y \mid C=c, a]=(1-p) E\left[Y \mid C^{*}=c, a\right]+p E\left[Y \mid C^{*}=c-1, a\right]+g(a),
$$

where $g(a)=E(g(m))$. Since the average $g(a)$ depends on $m$, it is important to keep a similar distribution of survey months when comparing different cohorts. Having this in mind, if all months of the year are included in the empirical analysis, from the definition $E\left[Y \mid C^{*}=c, m, a\right]=E\left[Y \mid C^{*}=c, a\right]+g(m, a)$, it follows that $g(a)$ is zero.

Solving equation (5) for the probability of being retired for the true cohort $c$, gives a 
recursive formula, in which this probability is a function of the observed probability, and the true probability of being retired for cohort $c-1$, that is,

$$
E\left[Y \mid C^{*}=c, a\right]=\frac{E[Y \mid C=c, a]-E\left[Y \mid C^{*}=c-1, a\right] p}{1-p}
$$

As a starting point for the recursion let us assume that the probability of being retired for cohort 1928 and 1927, 10 years before the treatment begins, are the same $E\left[Y \mid C^{*}=1927, a\right]=E\left[Y \mid C^{*}=1928, a\right]$, which implies that $E\left[Y \mid C^{*}=1928, a\right]=$ $E[Y \mid C=1928, a] .{ }^{9}$ Observing several pre-treatment cohorts allows us to properly control for preexisting trends toward earlier or later retirement. This recursion (with initial condition $\left.\operatorname{Pr}\left(C_{i}^{*}=1928\right) \in\{0,1\}\right)$ can be implemented using the the following regression

$$
y_{i}=\sum_{a=61}^{65} 1\left(A_{i}=a\right)\left(\sum_{c=1928}^{1940} \gamma_{a, c} \operatorname{Pr}\left(C_{i}^{*}=c\right)\right)+\gamma^{\prime} X_{i}+\epsilon_{i}
$$

where $\widehat{\gamma}_{a, c}$ is the empirical counterpart of $E\left[Y \mid C^{*}=c, a\right] .{ }^{10}$

The difference between the cohorts' cumulative distribution functions using the sophisticated method is equal to $\widehat{\beta}_{a, c}=\widehat{\gamma}_{a, c}-\widehat{\gamma}_{1937, c}$. In Section 4 I report the estimation results obtained using the three methods to correct for the misclassification error.

An easily interpretable result can be obtained from the sum of the estimated $\beta$ coefficients, which is equal to the difference between cohort $c$ and cohort 1937 average

\footnotetext{
${ }^{9}$ The empirical CDF of the two cohort are indeed very similar.

${ }^{10}$ Conditional on $c, a$, and $X=0$ :

$$
\begin{array}{r}
E[Y \mid C=c, a, X]=\gamma_{a, c} \operatorname{Pr}\left(C^{*}=c \mid C=c\right)+\gamma_{a, c-1} \operatorname{Pr}\left(C^{*}=c-1 \mid C=c\right) \\
=\gamma_{a, c}(1-p)+\gamma_{a, c-1} p
\end{array}
$$
}

Rearranging terms,

$$
\gamma_{a, c}=\frac{E[Y \mid C=c, a, X]-\gamma_{a, c-1} p}{1-p}
$$

which resembles equation (6). 
retirement age:

$$
\begin{aligned}
\Delta_{c} & =\sum_{a=62}^{66} a[\underset{c}{\operatorname{Pr}}(A=a)-\underset{37}{\operatorname{Pr}}(A=a)] \\
& =\sum_{a=62}^{66} a\left(\beta_{a, c}-\beta_{a-1, c}\right) \\
& =62\left(\beta_{62, c}-\beta_{61, c}\right)+\ldots+66\left(\beta_{66, c}-\beta_{65, c}\right) \\
& =62\left(\beta_{62, c}-0\right)+\ldots+66\left(0-\beta_{65, c}\right) \\
& =-\sum_{a=62}^{65} \beta_{a, c},
\end{aligned}
$$

where $\operatorname{Pr}_{c}(A=a)$ represents the fraction of workers born in year $c$ who retire at age $a$.

Finally, the difference between the post- and the pre-1937 cohort yearly trend of the average retirement age is simply a weighted average of the different $\Delta_{c} \mathrm{~s}$ :

$$
\Delta_{T-C}=\Delta_{T}+\Delta_{C}=\frac{1}{3} \sum_{c=38}^{40} \frac{\Delta_{c}}{|37-c|}+\frac{1}{9} \sum_{c=28}^{36} \frac{\Delta_{c}}{|37-c|}
$$

\section{Estimation Results}

Tables 2 and 3 contain the summary statistics of the full sample and the restricted sample. The cohorts are similar in terms of racial composition and household size, though younger cohorts tend to be more educated.

I estimate equation (3) separately for men and women. Table 4 and 5 show the results where the estimated distance between the cumulative distribution functions $\left(\widehat{\beta}_{2}\right)$ are only shown for workers born in 1936 or later, and the three different methods of correcting for misclassification are employed (sophisticated, naive, and restricted).

Columns (1), (3) and (5) contain only age and cohort dummies, where columns (2), (4) and (6) additionally control for marital status, education, race, total members of the

household, and geographic region. Controlling for these variables reduces the estimates 
only slightly. The main result is that for all three models and for both men and women, the estimated difference in CDFs between the 1938, 1939, and 1940 cohorts, and the 1937 cohort, is mostly negative. This indicates that in the 62 to 65 age range, the CDF of the 1937 cohort lies above the CDF of the other three cohorts, which means that workers born in 1938 retire later than workers born just one year earlier.

For each cohort Tables 6 and 7 report the sum of the estimated coefficients, the sample equivalent of equation (10). These estimates, multiplied by 12 to obtain monthly values, represent the change with respect to the 1937 cohort in the average retirement age. Although not all post-reform $\widehat{\beta}_{\mathrm{s}}$ are significant, most of the corresponding sums are significant at the one percent level, which suggests that the increase in the NRA generates an increase in the average retirement age. On the other hand, the differences between the CDFs before the reform tend to be smaller and not significant.

Table 8 shows the estimates of equation (11) (the slopes of the linear fit in Figure 1). The preexisting trend of the average retirement age is steeper for women than for men, but this can be explained by the change in socioeconomic factors. When controlling for demographic characteristics, for both men and women the preexisting trend is not significantly different from zero. In contrast, the trend among the treated cohorts is between 1 and 1.2 months (significant at the 1 percent level). Since every year the NRA is increasing by two months, the relative change is approximately 50 percent. Controlling for other variables seems to have only a small effect. Notice also that the naive method underestimates the effect by one-half.

These estimates are more than three times as large as previous out-of-sample predictions, which suggested that the labor supply response to the change in the NRA would be small. For example, Coile and Gruber (n.d.) simulate the effect on retirement of a one year increase in the NRA. Depending on the specification used, they predict that the average age of retirement should increase by between 0.5 and 2 months (using the 
61-65 age range). Similarly, Panis, Hurd, Loughran, Zissimopoulos, Haider and St.Clair (2002) predict an increase in the average retirement age of about seven days. Both studies rely on estimates based on the cross-sectional variation in labor supply that is related to differences in Social Security benefits.

Three major factors are likely to create a bias in out-of-sample predictions. First, present discounted values of future streams of benefits are likely to be measured with error. Second, these predictions do not capture the potential effect of unexpected benefit changes. Finally, simulations only account for the financial implications of the increase in the NRA, and not for any "norms" related to the NRA (i.e., the use of the NRA as a focal point as in Lumsdaine, Stock and Wise 1995). Axtell and Epstein (1999), for example, suggest that the spike in the distribution of retirement age at 65 may not entirely be the product of fully rational decision-making and may instead be the outcome of herd behavior.

Observing the actual changes avoids all three problems. Making use of an exact and exogenous reduction in Social Security benefits (and their present discounted value) gives estimates that account for changes potentially related to norms.

\subsection{Alternative Explanations}

The identification is based on the assumption that the observed trend-discontinuity in the average retirement age is due to the change in the NRA. Since for the treated cohorts the estimated $\beta_{2}$ s are negative at all ages, it is unlikely that yearly shocks are driving the results. Consider, for example, the stock market crisis of 2001. Workers with defined contribution plans may have reacted to such shocks by working longer in order to make up for financial losses. Yet, in 2000 there are already notable differences between the CDF of treated cohorts and untreated cohorts.

Also, at the time of the 2002-2003 stock market crisis, the youngest cohort (1940) is 
already 63 years old. Unless the effect related to the stock market crisis is heterogenous across ages, it will difference out when summing the $\beta$ s to get the effect on the average retirement age. Moreover, Coile and Levine (2004) find no evidence that changes in the stock market drive aggregate trends in labor supply. This is mainly due to the fact that, although 45 percent of all workers are covered by a pension plan, few of them have substantial stock holdings.

Another possible confounding effect is the 2000 Earnings Test removal. Earnings of Social Security beneficiaries above the earnings test threshold, up to their benefit amount, are taxed away at a 50 percent rate between age 62 and the NRA, and at a 33 percent rate between the NRA and 69 . The 33 percent rate was eliminated in 2000 . The benefits that are taxed away due to the earnings test are not lost, but postponed at an actuarially fair rate. Nevertheless, evidence suggests that people perceive the earnings test as a pure tax (Gruber and Orszag 2003).

If workers decide to continue working to reach the age at which they can work without being taxed, part of the change that I attribute to the NRA reform might be due to the earnings test removal. But several factors suggest that there is no confounding. First, in 2000, the oldest treated workers are only 62 years old. A confounding effect would only be possible if spillovers reach back more than three years. Second, the earnings test removal would generate a single change, not a change in the trend.

To exclude the possibility that results are driven by labor market shocks, I have estimated the same regression using weekly hours of work as the dependent variable (excluding retirees). There are no significant differences in hours of work across these cohorts. Also, the results are not driven by differences in part-time work or disability status. Excluding disabled workers, or part-time workers (those working less than 35 hours per week) from the analysis does not alter the results. ${ }^{11}$

\footnotetext{
${ }^{11}$ Since the benefits cuts do not apply to disability benefits, the disability insurance is becoming a more attractive alternative to retirement. Duggan, Singleton and Song (2005) find that workers born in or after 1938 are more likely to apply for SSA disability benefits than workers born between 1935 and 1937 ,
} 


\section{Conclusions}

An aging population and low labor force participation rates have worsened the financial situation of the Social Security trust fund. Aware of this in 1983, on the recommendation of the Greenspan commission, the U.S. Congress passed several reforms. Their aim was to cut benefits and increase labor force participation. Among other changes, the reform scheduled an increase in the normal retirement age (reducing the benefits) for workers born after 1938 .

I find evidence that workers reacted strongly to this increase in the NRA. The average retirement age for cohorts that are subject to increasing NRAs is rising by about 1 month every year, or 50 percent of the increase in the NRA. To obtain an estimated change in the average retirement trend that is based on more cohorts or on a wider age interval, the analysis presented here must be repeated in a few years. But given that there is intense, ongoing work to reform Social Security, conducting early analysis even with limited data is important.

Despite the 1983 reform, the Social Security trust fund is projected to become insolvent in 40 years. The Social Security projections are only one of several projections made by other institutions. A common feature of all projections is that they depend heavily on the way the future behavior is modeled. My results may help evaluate the importance of an increase in the NRA on labor force participation.

According to the 2003 Technical Panel on Assumptions and Methods (Technical Panel on Assumptions and Methods 2003), little documentation is available on how the trustees forecast labor force participation. The same panel explains that the method is based on three steps: the first is to estimate autoregressive labor force participation rates models

that control for economic, demographic, and policy variables for different groups based on "age, sex, marital status, and presence of children." For older people hazard rates are used but their estimates are quite small and do not affect my results. 
instead of LFPRs. Social Security benefits (relative to past earnings) and the fraction of workers affected by the Social Security earnings test are included in the regressions. The second step is to subjectively adjust some estimated coefficients based on economic theory, prior beliefs, and the "full mosaic" of all estimated models. The last step is to estimate fitted values based on projections of explanatory variables.

This model is likely to be accurate if changes are smooth over time. The problem is that the increase in the NRA may have introduced a break in the trend at the end of the period used by the trustees. Therefore, the break might be difficult to detect, especially if age groups (various birth years) are merged together.

According to the 2004 Trustees report "changes in available benefit levels from Social Security and increases in the normal retirement age, and the effects of modifying the earnings test are expected to encourage work at higher ages. Some of these factors are modeled directly." Nevertheless, the Social Security Advisory Board (Technical Panel on Assumptions and Methods 2003) recommends that "Social Security should be considered explicitly since it may result in higher participation rates." If the increase in NRA continues increasing the labor force participation of older workers, the trustees should follow this recommendation. 


\section{A Data}

I use the CPS monthly data from January 1989 to January 2006. The CPS data contain information about the respondent's age by the end of the survey week, usually the second week of the month. ${ }^{12}$ I restrict the data to individuals born between 1928 and 1940, aged 61-65. Workers who retire early need to wait at least until age 62 before claiming their benefits. Differences in retirement rates before 62 are therefore unlikely to be related to the increase in the NRA. However, these restrictions represent conservative choices and may underestimate the overall effect since, as will be shown later, differences in retirement rates under age 62 and above age 65 are small, indicating that the bias is likely to be small. The CPS has a much larger sample size than the Health and Retirement Survey (HRS). For each 1928-1940 birth cohort, aged between 61 and 65, there are around 60,000 observations, while the Health and Retirement Survey contains only 1000 observations for people born in 1937 and aged 61-63. Another advantage of the CPS data is that the data are published soon after the interviews take place. HRS data do not contain enough treated cohorts in the age range $62-65$.

The disadvantage of these data is that there is no information on Social Security insured status. Fortunately, almost all active and retired men and women above 62 are eligible for Social Security benefits (Panis, Hurd, Loughran, Zissimopoulos, Haider and St.Clair 2002). The analysis uses unweighted data. Using CPS weights, results are similar, but according to the Bureau of Labor Statistics weighting revisions affected the comparability of the CPS weights over time (Bowler, Ilg, Miller, Robison and Polivka 2003).

\footnotetext{
${ }^{12}$ The reference week for CPS is the week (Sunday through Saturday) of the month containing the 12th day.
} 


\section{B The inter-temporal model or retirement}

The first order conditions of the model are:

$$
\begin{aligned}
d z & : U_{W}\left(C_{t}\right)=U_{R}\left(C_{t}\right)-\mu\left(W_{z}-R_{z}(z)+\int_{z}^{D} e^{r(z-t)} \frac{\partial R_{t}(z)}{\partial z} d t\right) \\
d C & : \quad \frac{\partial U_{x}\left(C_{t}\right)}{\partial C_{t}}=\mu \quad x=W, R
\end{aligned}
$$

Given these assumptions, the system of equations that define the equilibrium is:

$$
\begin{aligned}
\epsilon C= & W-R\left(1+\frac{.05}{10}(z-N R A)\right)+R \frac{.05}{10}\left(\frac{1}{r}-\frac{1}{r} e^{r(z-D)}\right) \\
C & =\frac{1-e^{-r z}}{1-e^{-r D}} W+\frac{e^{-r z}-e^{-r D}}{1-e^{-r D}} R\left(1+\frac{.05}{10}(z-N R A)\right) \\
& =\alpha(z) W+(1-\alpha(z)) R\left(1+\frac{.05}{10}(z-N R A)\right)
\end{aligned}
$$

Totally differentiating:

$$
\begin{gathered}
\left(\begin{array}{ccc}
1 & \frac{r e^{-r z}}{1-e^{-r D}}\left(\left(1+\frac{.05}{10}(z-N R A)\right) R-W\right) \\
\epsilon & \frac{.05}{10} R\left(1+e^{r(z-D)}\right)
\end{array}\right)\left(\begin{array}{c}
d C \\
d 0
\end{array}\right) \\
=\left(\begin{array}{c}
-\frac{.05}{10} R \frac{e^{-r z}-e^{-r D}-e^{-r D}}{1-e^{-r D}} \\
\frac{.05}{10} R
\end{array}\right) d N R A
\end{gathered}
$$


and solving:

$$
=\frac{1}{\Delta}\left(\begin{array}{c}
.005 R\left(-1+e^{-r D}\right)\left(1+e^{-r(-z+D)}\right) \\
-\epsilon\left(-1+e^{-r D}\right) \\
r e^{-r z}(R-W)+.005 R e^{-r z}\left(r z-r N R A+e^{r(z-D)}-1\right) \\
\frac{d C}{d N R A}
\end{array}\right)
$$

where

$$
\begin{array}{r}
\Delta=\frac{.05}{10} R\left(\left(1+e^{-r(-z+D)}\right)\left(-1+e^{-r D}\right)+\epsilon e^{-r z}\left(r(z-N R A)+e^{r(z-D)}-1\right)\right. \\
-\epsilon r e^{-r z}(W-R) .
\end{array}
$$

Notice that if $r(z-N R A)+e^{r(z-D)}-1<0$, then $\Delta<0$. The first expression can only be positive if the worker retires after his or her NRA $(z>N R A)$ and the interest rate is extremely large. It follows that for reasonable parameters the retirement age increases when the NRA increases,

$$
\frac{d z}{d N R A}=\frac{\frac{.05}{10} R}{\Delta}\left(-\epsilon\left(e^{-r z}-e^{-r D}\right)-1+e^{-r D}\right)>0
$$

while consumption decreases if,

$$
\frac{d C}{d N R A}=\frac{\left(\frac{.05}{10} R\right)^{2}}{\Delta} e^{-r z}\left(e^{r(z-D)}\left(1-e^{r(z-D)}\right)+r\left(\frac{R-W}{\frac{.05}{10} R}+z-N R A\right)\right)<0
$$

or

$$
e^{r(z-D)}\left(1-e^{r(z-D)}\right)+r\left(\frac{R-W}{\frac{.05}{10} R}+z-N R A\right)>0
$$

Notice that the first term is always positive, while the second is not. Now assume that 
an increase of $N R A$ to $N R A^{\prime}$ has not been anticipated. Up to time $z$ the worker behaves as in the previous case

$$
\begin{gathered}
\epsilon C=W-R\left(1+\frac{.05}{10}(z-N R A)\right)+R \frac{.05}{10}\left(\frac{1}{r}-\frac{1}{r} e^{r(z-D)}\right) \\
C=\frac{1-e^{-r z}}{1-e^{-r D}} W+\frac{e^{-r z}-e^{-r D}}{1-e^{-r D}} R\left(1+\frac{.05}{10}(z-N R A)\right)
\end{gathered}
$$

After time $z$, the new objective is:

$$
\max _{z, C_{t}} V(z)=\int_{z}^{z^{\prime}} e^{-r t} U_{W}\left(C_{t}\right) d t+\int_{z^{\prime}}^{D} e^{-r t} U_{R}\left(C_{t}\right) d t
$$

s.t.

$$
\int_{0}^{z} e^{-r t} C_{t} d t+\int_{z}^{D} C_{t}^{\prime} d t=\int_{0}^{z^{\prime}} e^{-r t} W_{t} d t+\int_{z^{\prime}}^{D} e^{-r t} R_{t} d t
$$

or simplifying as before, s.t.

$$
C\left(1-e^{-r z}\right)+C^{\prime}\left(e^{-r z}-e^{-r D}\right)=\left(1-e^{-r z^{\prime}}\right) W+\left(e^{-r z^{\prime}}-e^{-r D}\right) R\left(1+\frac{.05}{10}\left(z^{\prime}-N R A^{\prime}\right)\right)
$$

Combining the FOCs:

$$
\epsilon C^{\prime}=W-R\left(1+\frac{.05}{10}\left(z^{\prime}-N R A^{\prime}\right)\right)+R \frac{.05}{10}\left(\frac{1}{r}-\frac{1}{r} e^{r\left(z^{\prime}-D\right)}\right)
$$




$$
\begin{aligned}
\left(\begin{array}{ccc}
1 & \frac{-r e^{-r z^{\prime}}}{e^{-r z}-e^{-r D}} W+\frac{r e^{-r z^{\prime}}}{e^{-r z}-e^{-r D}}\left(1+\frac{.05}{10}\left(z^{\prime}-N R A^{\prime}\right)\right) R-\frac{.05}{10} R \frac{e^{-r z^{\prime}}-e^{-r D}}{e^{-r z}-e^{-r D}} \\
\epsilon & \frac{.05}{10} R\left(1+e^{r(z-D)}\right)
\end{array}\right)\left(\begin{array}{c}
d C^{\prime} \\
d z^{\prime}
\end{array}\right) \\
=\left(\begin{array}{c}
-\frac{.05}{10} R \frac{e^{-r z^{\prime}}-e^{-r D}}{e^{-r z}-e^{-r D}} \\
\frac{.05}{10} R
\end{array}\right) d N R A^{\prime}
\end{aligned}
$$

$$
\begin{array}{r}
\left(\begin{array}{c}
\frac{d C^{\prime}}{d N R A^{\prime}} \\
\frac{d z^{\prime}}{d N R A^{\prime}}
\end{array}\right)=\left(\begin{array}{cc}
1 & \frac{-r e^{-r z^{\prime}}}{e^{-r z}-e^{-r D}} W+\frac{r e^{-r z^{\prime}}}{e^{-r z}-e^{-r D}}\left(1+\frac{.05}{10}\left(z^{\prime}-N R A^{\prime}\right)\right) R-\frac{.05}{10} R \frac{e^{-r z^{\prime}}-e^{-r D}}{e^{-r z}-e^{-r D}} \\
\epsilon & \frac{.05}{10} R\left(1+e^{r(z-D)}\right)
\end{array}\right)^{-1} \\
\left(\begin{array}{c}
-\frac{.05}{10} R \frac{e^{-r z}-e^{-r D}}{1-e^{-r D}} \\
\frac{.05}{10} R
\end{array}\right)
\end{array}
$$

Solving gives that

$$
\frac{d z^{\prime}}{d N R A^{\prime}}=\frac{\frac{.05}{10} R}{\Delta^{\prime}}\left[-\epsilon\left(e^{-r z^{\prime}}-e^{-r D}\right)-e^{-r z}+e^{-r D}\right]>0
$$

where

$$
\begin{array}{r}
\Delta^{\prime}=.005 R\left(\left(1+e^{r(z-D)}\right)\left(e^{-r D}-e^{-r z^{\prime}}\right)+\epsilon e^{-r z}\left(r(z-N R A)+e^{-r(D-z)}-1\right)\right) \\
-\epsilon r e^{-r z}(W-R)<0 .
\end{array}
$$

To show that the myopic worker has, ceteris paribus, a higher optimal age of retirement after the an increase of $N R A$, I evaluate $\frac{d z}{d N R A}$ at $N R A^{\prime}=N R A$ and $z=z^{\prime}$. To show that

$$
\frac{d z^{\prime}}{d N R A^{\prime}}\left(N R A^{\prime}=N R A, z=z^{\prime}\right)>\frac{d z}{d N R A}
$$


after some algebra, it is sufficient to show that,

$$
e^{r(z-D)}\left(1-e^{r(z-D)}\right)+r\left(\frac{R-W}{\frac{.05}{10} R}+z-N R A\right)>0
$$

which is the same condition that determines consumption decreases when benefits are cut. 


\section{References}

Aguiar, Mark and Erik Hurst. "Consumption versus Expenditure." Journal of Political Economy 113-5 (October 2005): 919-948.

Aigner, Dennis J. "Regression With a Binary Independent Variable Subject to Errors of Observation." Journal of Econometrics 1-1 (March 1973): 4960.

Anderson, Michael, Ronald Lee, and Shripad Tuljapurkar. "Stochastic Forecasts of the Social Security Trust Fund." CEDA Papers 20030005CL: Center for the Economics and Demography of Aging, University of California, Berkeley 2003.

Axtell, Robert L. and Joshua M. Epstein. "Coordination in Transient Social Networks." in Henry Aaron, ed., Behavioral Dimensions of Retirement Economics, Brookings Institution Press \& Russell Sage Foundation, 1999: pp. 161-183.

Bowler, Mary, Randy E. Ilg, Stephen Miller, Ed Robison, and Anne Polivka. "Revisions to the Current Population Survey Effective in January 2003." Employment and Earnings: Bureau of Labor Statistics, February 2003. http://www.bls.gov/cps/cpsoccind.htm.

Burtless, Gary. "Social Security, Unanticipated Benefit Increases, and the Timing of Retirement." Review of Economic Studies 53-5 (October 1986): 781-805.

Card, David and Alan B. Krueger. "Does School Quality Matter? Returns to Education and the Characteristics of Public Schools in the United States." Journal of Political Economy 100-1 (February 1992): 1-40.

Coile, Courtney C. and Jonathan Gruber. "Social Security and Retirement." Review of Economics and Statistics. forthcoming.

and Phillip B. Levine. "Bulls, Bears, and Retirement Behavior." NBER Working Papers: National Bureau of Economic Research, Inc, September 2004. 
Duggan, Mark, Perry Singleton, and Jae Song. "Aching to Retire? The Rise in the Full Retirement Age and its Impact on the Disability Rolls." NBER Working Papers 11811: National Bureau of Economic Research, Inc, December 2005.

Fields, Gary S. and Olivia S. Mitchell. "The Effects of Social Security Reforms on Retirement Ages and Retirement Incomes." Journal of Public Economics 25 (Winter 1984): 143159.

Gruber, Jonathan and Peter Orszag. "Does the Social Security Earnings Test Affect Labor Supply and Benefits Receipt?" National Tax Journal 4-56 (773 2003): 755.

Gustman, Alan L and Thomas L Steinmeier. "The 1983 Social Security Reforms and Labor Supply Adjustments of Older Individuals in the Long Run." Journal of Labor Economics 3-2 (April 1985): 237-53.

Krueger, Alan B. and Jorn-Steffen Pischke. "The Effect of Social Security on Labor Supply: A Cohort Analysis of the Notch Generation." Journal of Labor Economics 10-4 (October 1992): 412-37.

Lumsdaine, Robin, James H. Stock, and David A. Wise. "Why are Retirement Rates so High at Age 65?" in David A. Wise, ed., Advances in the Economics of Aging, University of Chicago Press, 1996: pp. 61-82.

Madrian, Brigitte C. and Lars John Lefgren. "A Note on Longitudinally Matching Current Population Survey (CPS) Respondents." NBER Technical Working Papers 0247: National Bureau of Economic Research, Inc, November 1999.

Mastrobuoni, Giovanni. "Do better-informed workers make better retirement choices? A test based on the Social Security Statement." (April 2006). mimeo.

. "The Social Security Earnings Test Removal. Money Saved or Money Spent by the Trust Fund?" CEPS Working Paper 133: Princeton University, August 2006. 
Panis, Constantijn, Michael Hurd, David Loughran, Julie Zissimopoulos, Steven Haider, and Patricia St.Clair. "The Effects of Changing Social Security Administration's Early Entitlement Age and the Normal Retirement Age." report for the SSA: RAND 2002.

Quinn, Joseph F. "Has the Early Retirement Trend Reversed?" Manuscript 424: Boston College Department of Economics, May 1999.

Technical Panel on Assumptions and Methods. Report to the Social Security Advisory Board. Washington D.C.: 2003. 

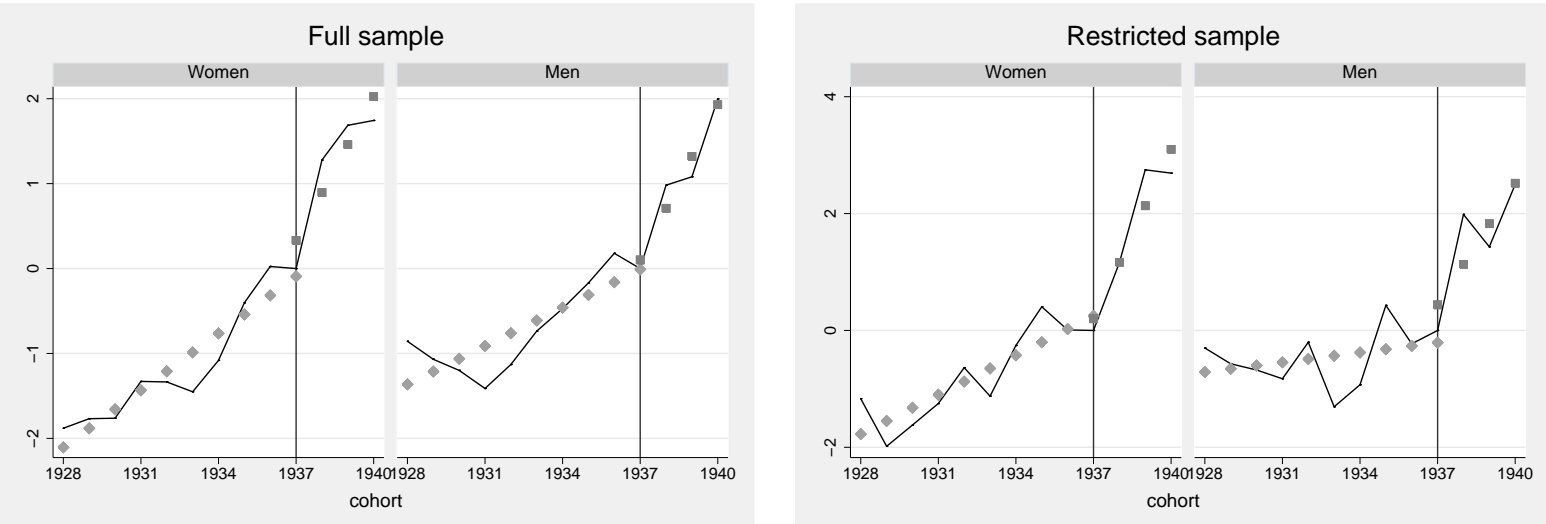

Figure 1: Change in the average retirement age (in months) with respect to the 1937 birth cohort (solid line) and its piecewise linear fit (dots).

NOTE.- Based on individuals between age 62 and 65 .
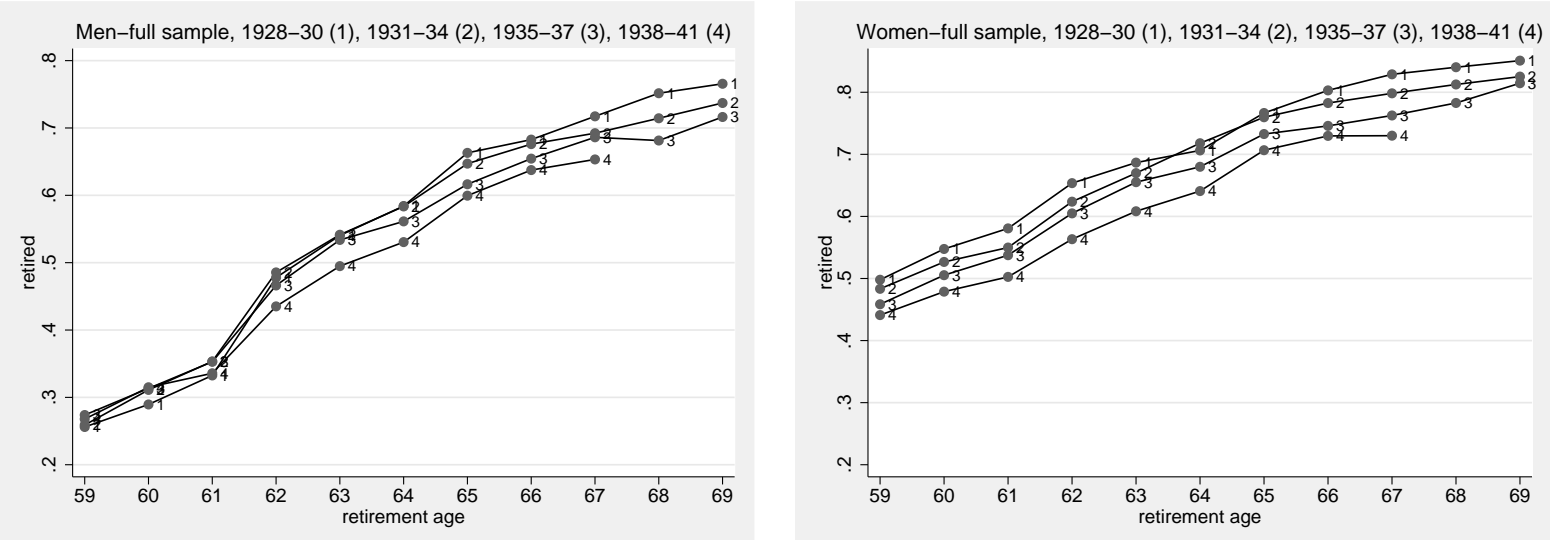

Figure 2: Cumulative distribution function of retirement age. Full sample.
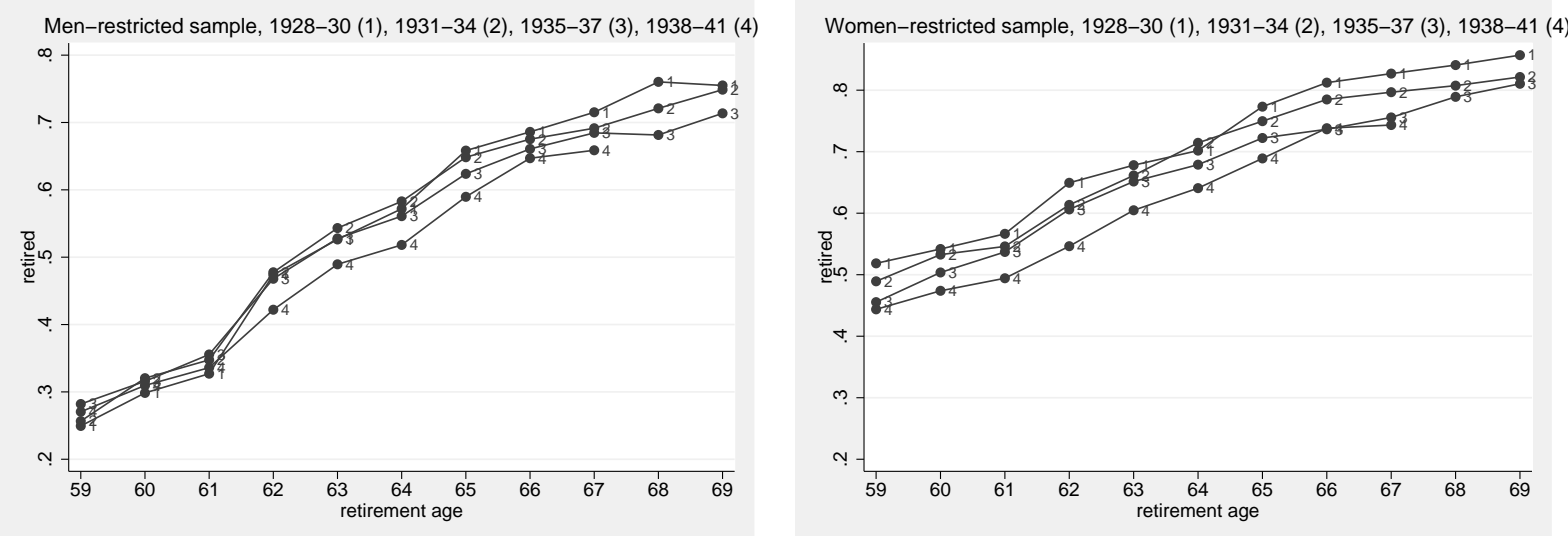

Figure 3: Cumulative distribution function of retirement age. Restricted sample. 
Table 1: EMPIRICAL AND UNIFORM DISTRIBUTION OF MONTHS OF BIRTH.

\begin{tabular}{l|cccc}
\hline \hline Month & Emprical & Empirical CDF & Uniform & Uniform CDF \\
\hline 1 & 9.28 & 9.28 & 8.33 & 8.33 \\
2 & 8.17 & 17.45 & 8.33 & 16.67 \\
3 & 8.72 & 26.16 & 8.33 & 25.00 \\
4 & 8.51 & 34.68 & 8.33 & 33.33 \\
5 & 7.97 & 42.65 & 8.33 & 41.67 \\
6 & 8.28 & 50.93 & 8.33 & 50.00 \\
7 & 9.14 & 60.07 & 8.33 & 58.33 \\
8 & 9.79 & 69.86 & 8.33 & 66.67 \\
9 & 8.26 & 78.12 & 8.33 & 75.00 \\
10 & 7.56 & 85.68 & 8.33 & 83.33 \\
11 & 8.27 & 93.95 & 8.33 & 91.67 \\
12 & 6.05 & 100 & 8.33 & 100.00 \\
\hline
\end{tabular}

NOTE.- The empirical distribution is based on 7801 certain matches born between 1937 and 1939 and aged 61 to 65 .

Table 2: SUMMARY STATISTICS OF THE SAMPLE AGED 61-65 (FULL SAMPLE).

\begin{tabular}{|c|c|c|c|c|c|c|c|c|}
\hline & \multicolumn{2}{|c|}{ 1928-1930 } & \multicolumn{2}{|c|}{ 1931-1934 } & \multicolumn{2}{|c|}{ 1935-1937 } & \multicolumn{2}{|c|}{ 1938-1941 } \\
\hline & Mean & $\begin{array}{l}\mathrm{SD} \\
\end{array}$ & Mean & SD & Mean & SD & Mean & SD \\
\hline Age & 62.93 & 1.41 & 62.91 & 1.42 & 63.03 & 1.43 & 63.05 & 1.41 \\
\hline Year & 1992.2 & 1.73 & 1995.8 & 1.91 & 1999.5 & 1.74 & 2002.2 & 1.59 \\
\hline Male & 0.46 & 0.50 & 0.47 & 0.50 & 0.48 & 0.50 & 0.47 & 0.50 \\
\hline Retired (NILF) & 60.41 & 48.90 & 59.21 & 49.15 & 57.87 & 49.38 & 55.28 & 49.72 \\
\hline Employed & 38.06 & 48.55 & 39.31 & 48.84 & 40.90 & 49.17 & 43.31 & 49.55 \\
\hline Not married & 0.28 & 0.45 & 0.29 & 0.5 & 0.29 & 0.46 & 0.30 & 0.46 \\
\hline$<$ High Sc. & 0.27 & 0.44 & 0.25 & 0.43 & 0.21 & 0.41 & 0.18 & 0.39 \\
\hline Some college & 0.14 & 0.35 & 0.14 & 0.35 & 0.15 & 0.36 & 0.16 & 0.36 \\
\hline College & 0.21 & 0.41 & 0.23 & 0.42 & 0.26 & 0.44 & 0.28 & 0.45 \\
\hline Black & 0.08 & 0.28 & 0.09 & 0.29 & 0.10 & 0.29 & 0.09 & 0.28 \\
\hline Asian & 0.02 & 0.15 & 0.03 & 0.17 & 0.03 & 0.17 & 0.03 & 0.17 \\
\hline Other race & 0.01 & 0.10 & 0.01 & 0.10 & 0.01 & 0.10 & 0.01 & 0.12 \\
\hline$\# \mathrm{HH}=1$ & 0.17 & 0.38 & 0.17 & 0.37 & 0.17 & 0.38 & 0.18 & 0.38 \\
\hline$\# \mathrm{HH}>2$ & 0.24 & 0.43 & 0.23 & 0.42 & 0.22 & 0.41 & 0.21 & 0.41 \\
\hline Midwest & 0.24 & 0.43 & 0.23 & 0.42 & 0.23 & 0.42 & 0.24 & 0.43 \\
\hline South & 0.31 & 0.46 & 0.33 & 0.47 & 0.33 & 0.47 & 0.31 & 0.46 \\
\hline West & 0.19 & 0.40 & 0.20 & 0.40 & 0.22 & 0.41 & 0.23 & 0.42 \\
\hline
\end{tabular}

NOTE.- SD denotes the standard deviation. There are 828,535 observations. 
Table 3: SUMMARY STATISTICS OF THE SAMPLE AGED 61-65 (RESTRICTED SAMPLE).

\begin{tabular}{|c|c|c|c|c|c|c|c|c|}
\hline & \multicolumn{2}{|c|}{ 1928-1930 } & \multicolumn{2}{|c|}{ 1931-1934 } & \multicolumn{2}{|c|}{ 1935-1937 } & \multicolumn{2}{|c|}{ 1938-1941 } \\
\hline & Mean & SD & Mean & SD & Mean & SD & Mean & SD \\
\hline Age & 62.92 & 1.41 & 62.91 & 1.42 & 63.02 & 1.43 & 63.03 & 1.41 \\
\hline Year & 1992.1 & 1.71 & 1995.7 & 1.91 & 1999.4 & 1.74 & 2002.1 & 1.60 \\
\hline Male & 0.46 & 0.50 & 0.47 & 0.50 & 0.47 & 0.50 & 0.47 & 0.50 \\
\hline Retired (NILF) & 59.76 & 49.04 & 58.76 & 49.23 & 57.75 & 49.40 & 54.08 & 49.83 \\
\hline Employed & 38.71 & 48.71 & 39.65 & 48.92 & 41.03 & 49.19 & 44.39 & 49.69 \\
\hline Not married & 0.28 & 0.45 & 0.29 & 0.46 & 0.30 & 0.46 & 0.31 & 0.46 \\
\hline$<$ High Sc. & 0.27 & 0.44 & 0.25 & 0.43 & 0.21 & 0.41 & 0.19 & 0.39 \\
\hline Some college & 0.14 & 0.35 & 0.14 & 0.35 & 0.15 & 0.36 & 0.16 & 0.37 \\
\hline College & 0.21 & 0.41 & 0.23 & 0.42 & 0.26 & 0.44 & 0.28 & 0.45 \\
\hline Black & 0.08 & 0.27 & 0.09 & 0.28 & 0.09 & 0.29 & 0.09 & 0.29 \\
\hline Asian & 0.02 & 0.15 & 0.03 & 0.17 & 0.03 & 0.17 & 0.03 & 0.16 \\
\hline Other race & 0.01 & 0.09 & 0.01 & 0.11 & 0.01 & 0.10 & 0.01 & 0.12 \\
\hline$\# \mathrm{HH}=1$ & 0.18 & 0.38 & 0.18 & 0.38 & 0.18 & 0.39 & 0.19 & 0.39 \\
\hline$\# \mathrm{HH}>2$ & 0.24 & 0.43 & 0.23 & 0.42 & 0.21 & 0.41 & 0.20 & 0.40 \\
\hline Midwest & 0.24 & 0.43 & 0.24 & 0.43 & 0.23 & 0.42 & 0.24 & 0.43 \\
\hline South & 0.31 & 0.46 & 0.32 & 0.47 & 0.33 & 0.47 & 0.31 & 0.46 \\
\hline West & 0.19 & 0.40 & 0.20 & 0.40 & 0.22 & 0.41 & 0.23 & 0.42 \\
\hline
\end{tabular}

NOTE.- SD denotes the standard deviation. There are 158,959 observations. 
Table 4: ESTIMATED DIFFERENCES (IN PERCENT) IN THE CDFs OF RETIREMENT AGE FOR FEMALES IN THE SAMPLE.

\begin{tabular}{|c|c|c|c|c|c|c|}
\hline \multirow{3}{*}{ Age 61\&Coh.36 } & \multirow{2}{*}{\multicolumn{2}{|c|}{$\begin{array}{l}(1) \quad(2) \\
\text { Sophisticated }\end{array}$}} & $(3)$ & $(4)$ & (5) & $(6)$ \\
\hline & & & \multicolumn{2}{|c|}{ Naive } & \multicolumn{2}{|c|}{ Restricted } \\
\hline & $\begin{array}{c}-6.5 \\
(2.0)^{* *}\end{array}$ & $\begin{array}{c}-6.7 \\
(1.9)^{* *}\end{array}$ & $\begin{array}{c}-3.7 \\
(1.4)^{* *}\end{array}$ & $\begin{array}{c}-4.2 \\
(1.3)^{* *}\end{array}$ & $\begin{array}{c}-6.9 \\
(2.3)^{* *}\end{array}$ & $\begin{array}{c}-7.0 \\
(2.3)^{* *}\end{array}$ \\
\hline Age $62 \&$ Coh. 36 & $\begin{array}{l}-3.7 \\
(1.9)\end{array}$ & $\begin{array}{c}-4.0 \\
(1.9)^{*}\end{array}$ & $\begin{array}{l}-1.9 \\
(1.3)\end{array}$ & $\begin{array}{c}-2.4 \\
(1.3)\end{array}$ & $\begin{array}{l}-3.4 \\
(2.3)\end{array}$ & $\begin{array}{l}-3.6 \\
(2.3)\end{array}$ \\
\hline Age $63 \&$ Coh. 36 & $\begin{array}{c}1.8 \\
(1.9)\end{array}$ & $\begin{array}{c}1.4 \\
(1.9)\end{array}$ & $\begin{array}{c}2.0 \\
(1.3)\end{array}$ & $\begin{array}{c}1.6 \\
(1.3)\end{array}$ & $\begin{array}{c}2.2 \\
(2.3)\end{array}$ & $\begin{array}{c}1.3 \\
(2.3)\end{array}$ \\
\hline Age $64 \&$ Coh.36 & $\begin{array}{c}1.0 \\
(1.8)\end{array}$ & $\begin{array}{c}0.2 \\
(1.8)\end{array}$ & $\begin{array}{c}0.7 \\
(1.3)\end{array}$ & $\begin{array}{c}0.0 \\
(1.2)\end{array}$ & $\begin{array}{c}1.7 \\
(2.2)\end{array}$ & $\begin{array}{c}0.6 \\
(2.2)\end{array}$ \\
\hline Age $65 \&$ Coh. 36 & $\begin{array}{c}-2.4 \\
(1.7)\end{array}$ & $\begin{array}{c}-2.4 \\
(1.6)\end{array}$ & $\begin{array}{c}-1.0 \\
(1.1)\end{array}$ & $\begin{array}{c}-1.1 \\
(1.1)\end{array}$ & $\begin{array}{l}-0.5 \\
(2.0)\end{array}$ & $\begin{array}{l}-1.1 \\
(2.0)\end{array}$ \\
\hline Age $61 \&$ Coh.38 & $\begin{array}{c}-3.4 \\
(1.9)\end{array}$ & $\begin{array}{c}-3.1 \\
(1.9)\end{array}$ & $\begin{array}{l}-1.8 \\
(1.3)\end{array}$ & $\begin{array}{c}-1.6 \\
(1.3)\end{array}$ & $\begin{array}{l}-1.7 \\
(2.2)\end{array}$ & $\begin{array}{l}-1.3 \\
(2.2)\end{array}$ \\
\hline Age $62 \&$ Coh. 38 & $\begin{array}{c}-5.0 \\
(1.9)^{* *}\end{array}$ & $\begin{array}{c}-4.7 \\
(1.9)^{*}\end{array}$ & $\begin{array}{c}-3.1 \\
(1.3)^{*}\end{array}$ & $\begin{array}{c}-2.8 \\
(1.3)^{*}\end{array}$ & $\begin{array}{l}-4.4 \\
(2.3)\end{array}$ & $\begin{array}{c}-4.4 \\
(2.2)^{*}\end{array}$ \\
\hline Age $63 \&$ Coh. 38 & $\begin{array}{l}-2.2 \\
(1.9)\end{array}$ & $\begin{array}{l}-1.7 \\
(1.8)\end{array}$ & $\begin{array}{l}-2.0 \\
(1.3)\end{array}$ & $\begin{array}{c}-1.6 \\
(1.3)\end{array}$ & $\begin{array}{l}-0.5 \\
(2.3)\end{array}$ & $\begin{array}{l}-0.8 \\
(2.3)\end{array}$ \\
\hline Age $64 \&$ Coh. 38 & $\begin{array}{c}-4.2 \\
(1.8)^{*}\end{array}$ & $\begin{array}{c}-3.9 \\
(1.7)^{*}\end{array}$ & $\begin{array}{c}-3.3 \\
(1.2)^{* *}\end{array}$ & $\begin{array}{c}-3.0 \\
(1.2)^{* *}\end{array}$ & $\begin{array}{l}-3.0 \\
(2.2)\end{array}$ & $\begin{array}{l}-3.1 \\
(2.1)\end{array}$ \\
\hline Age $65 \&$ Coh. 38 & $\begin{array}{c}-3.7 \\
(1.7)^{*}\end{array}$ & $\begin{array}{c}-3.4 \\
(1.6)^{*}\end{array}$ & $\begin{array}{c}-2.2 \\
(1.1)^{*}\end{array}$ & $\begin{array}{c}-2.1 \\
(1.1)\end{array}$ & $\begin{array}{l}-1.8 \\
(2.0)\end{array}$ & $\begin{array}{l}-1.8 \\
(2.0)\end{array}$ \\
\hline Age $61 \&$ Coh.39 & $\begin{array}{c}-4.1 \\
(1.8)^{*}\end{array}$ & $\begin{array}{c}-3.6 \\
(1.7)^{*}\end{array}$ & $\begin{array}{c}-2.9 \\
(1.4)^{*}\end{array}$ & $\begin{array}{c}-2.6 \\
(1.3)\end{array}$ & $\begin{array}{c}-5.4 \\
(2.3)^{*}\end{array}$ & $\begin{array}{c}-4.7 \\
(2.3)^{*}\end{array}$ \\
\hline Age $62 \&$ Coh.39 & $\begin{array}{c}-6.4 \\
(1.7)^{* *}\end{array}$ & $\begin{array}{c}-5.1 \\
(1.6)^{* *}\end{array}$ & $\begin{array}{c}-4.9 \\
(1.3)^{* *}\end{array}$ & $\begin{array}{c}-3.9 \\
(1.3)^{* *}\end{array}$ & $\begin{array}{c}-9.4 \\
(2.3)^{* *}\end{array}$ & $\begin{array}{c}-8.7 \\
(2.2)^{* *}\end{array}$ \\
\hline Age $63 \&$ Coh.39 & $\begin{array}{c}-3.7 \\
(1.7)^{*}\end{array}$ & $\begin{array}{l}-2.5 \\
(1.6)\end{array}$ & $\begin{array}{c}-3.4 \\
(1.3)^{*}\end{array}$ & $\begin{array}{c}-2.3 \\
(1.3)\end{array}$ & $\begin{array}{c}-4.9 \\
(2.3)^{*}\end{array}$ & $\begin{array}{l}-4.3 \\
(2.2)\end{array}$ \\
\hline Age $64 \&$ Coh.39 & $\begin{array}{l}-2.2 \\
(1.6)\end{array}$ & $\begin{array}{l}-2.0 \\
(1.5)\end{array}$ & $\begin{array}{c}-2.8 \\
(1.2)^{*}\end{array}$ & $\begin{array}{c}-2.4 \\
(1.2)^{*}\end{array}$ & $\begin{array}{l}-3.5 \\
(2.2)\end{array}$ & $\begin{array}{l}-3.2 \\
(2.1)\end{array}$ \\
\hline Age $65 \&$ Coh.39 & $\begin{array}{c}-4.2 \\
(1.5)^{* *}\end{array}$ & $\begin{array}{c}-3.5 \\
(1.5)^{*}\end{array}$ & $\begin{array}{c}-3.0 \\
(1.2)^{*}\end{array}$ & $\begin{array}{c}-2.4 \\
(1.2)^{*}\end{array}$ & $\begin{array}{c}-5.2 \\
(2.1)^{*}\end{array}$ & $\begin{array}{c}-4.7 \\
(2.0)^{*}\end{array}$ \\
\hline Age $61 \&$ Coh. 40 & $\begin{array}{c}-9.3 \\
(2.0)^{* *}\end{array}$ & $\begin{array}{c}-8.3 \\
(1.9)^{* *}\end{array}$ & $\begin{array}{c}-7.0 \\
(1.5)^{* *}\end{array}$ & $\begin{array}{c}-6.4 \\
(1.5)^{* *}\end{array}$ & $\begin{array}{c}-10.1 \\
(2.5)^{* *}\end{array}$ & $\begin{array}{c}-8.7 \\
(2.4)^{* *}\end{array}$ \\
\hline Age $62 \&$ Coh. 40 & $\begin{array}{c}-6.8 \\
(2.0)^{* *}\end{array}$ & $\begin{array}{c}-6.0 \\
(2.0)^{* *}\end{array}$ & $\begin{array}{c}-5.3 \\
(1.6)^{* *}\end{array}$ & $\begin{array}{c}-4.6 \\
(1.5)^{* *}\end{array}$ & $\begin{array}{c}-11.4 \\
(2.5)^{* *}\end{array}$ & $\begin{array}{c}-10.6 \\
(2.4)^{* *}\end{array}$ \\
\hline Age $63 \&$ Coh. 40 & $\begin{array}{l}-3.5 \\
(2.0)\end{array}$ & $\begin{array}{l}-3.1 \\
(2.0)\end{array}$ & $\begin{array}{l}-2.9 \\
(1.6)\end{array}$ & $\begin{array}{l}-2.3 \\
(1.5)\end{array}$ & $\begin{array}{c}-5.9 \\
(2.5)^{*}\end{array}$ & $\begin{array}{c}-5.4 \\
(2.5)^{*}\end{array}$ \\
\hline Age $64 \&$ Coh. 40 & $\begin{array}{c}-4.8 \\
(1.9)^{*}\end{array}$ & $\begin{array}{c}-4.0 \\
(1.9)^{*}\end{array}$ & $\begin{array}{c}-3.4 \\
(1.5)^{*}\end{array}$ & $\begin{array}{l}-2.8 \\
(1.5)\end{array}$ & $\begin{array}{l}-4.6 \\
(2.4)\end{array}$ & $\begin{array}{l}-3.7 \\
(2.4)\end{array}$ \\
\hline Age $65 \&$ Coh. 40 & $\begin{array}{c}-4.4 \\
(1.8)^{*}\end{array}$ & $\begin{array}{c}-2.8 \\
(1.8)\end{array}$ & $\begin{array}{c}-3.1 \\
(1.4)^{*}\end{array}$ & $\begin{array}{l}-1.8 \\
(1.4)\end{array}$ & $\begin{array}{c}-5.4 \\
(2.3)^{*}\end{array}$ & $\begin{array}{l}-4.0 \\
(2.3)\end{array}$ \\
\hline Other $X \mathrm{~s}$ & no & yes & no & yes & no & yes \\
\hline Observations & 440157 & 440157 & 420785 & 420785 & 84682 & 84682 \\
\hline R-squared & 0.66 & 0.67 & 0.66 & 0.67 & 0.65 & 0.67 \\
\hline
\end{tabular}

NOTE.- Standard errors clustered by individuals in parentheses, ${ }^{*}$ significant at 5 percent, ${ }^{* *}$ significant at 1 percent. Other $X$ s include marital status, education, race, total members of the household and geographic region. 
Table 5: ESTIMATED DIFFERENCES (IN PERCENT) IN THE CDFs OF RETIREMENT AGE FOR MALES IN THE SAMPLE.

\begin{tabular}{|c|c|c|c|c|c|c|}
\hline \multirow{4}{*}{ Age 61\&Coh.36 } & (1) & $(2)$ & (3) & $(4)$ & $(5)$ & $(6)$ \\
\hline & \multicolumn{2}{|c|}{ Sophisticated } & \multicolumn{2}{|c|}{ Naive } & \multicolumn{2}{|c|}{ Restricted } \\
\hline & 0.7 & 0.6 & 2.0 & 2.0 & 0.2 & 0.9 \\
\hline & $(2.0)$ & (1.9) & (1.3) & $(1.3)$ & $(2.4)$ & $(2.3)$ \\
\hline \multirow[t]{2}{*}{ Age $62 \&$ Coh.36 } & -3.2 & -3.4 & -0.1 & -0.0 & 0.8 & 1.0 \\
\hline & $(2.0)$ & (1.9) & $(1.3)$ & $(1.3)$ & $(2.4)$ & $(2.3)$ \\
\hline \multirow[t]{2}{*}{ Age $63 \&$ Coh.36 } & -2.2 & -2.2 & -1.3 & -1.3 & -0.7 & -0.4 \\
\hline & $(2.1)$ & $(2.1)$ & $(1.5)$ & (1.4) & $(2.5)$ & $(2.5)$ \\
\hline \multirow[t]{2}{*}{ Age $64 \&$ Coh.36 } & 0.6 & -0.0 & 0.6 & 0.2 & 2.2 & 1.5 \\
\hline & $(2.1)$ & $(2.0)$ & (1.4) & $(1.4)$ & $(2.5)$ & $(2.5)$ \\
\hline \multirow[t]{2}{*}{ Age $65 \&$ Coh. 36} & -1.9 & -2.5 & -0.8 & -1.2 & -0.5 & -1.1 \\
\hline & $(1.8)$ & $(1.8)$ & $(1.2)$ & $(1.2)$ & $(2.3)$ & $(2.2)$ \\
\hline \multirow[t]{2}{*}{ Age $61 \&$ Coh.38 } & -2.9 & -2.5 & -1.8 & -1.3 & -4.4 & -4.2 \\
\hline & (1.9) & $(1.8)$ & $(1.3)$ & $(1.2)$ & $(2.3)$ & $(2.2)$ \\
\hline \multirow[t]{2}{*}{ Age $62 \&$ Coh. 38} & -4.6 & -4.4 & -1.5 & -1.2 & -6.2 & -6.1 \\
\hline & $(2.0)^{*}$ & $(2.0)^{*}$ & (1.4) & (1.4) & $(2.4)^{*}$ & $(2.4)^{*}$ \\
\hline \multirow[t]{2}{*}{ Age $63 \&$ Coh.38 } & -6.4 & -6.2 & -4.0 & -3.7 & -3.4 & -2.6 \\
\hline & $(2.0)^{* *}$ & $(2.0)^{* *}$ & $(1.4)^{* *}$ & $(1.4)^{* *}$ & $(2.5)$ & $(2.5)$ \\
\hline \multirow[t]{2}{*}{ Age $64 \&$ Coh.38 } & -2.2 & -2.1 & -1.8 & -1.6 & -3.2 & -3.1 \\
\hline & $(2.0)$ & $(1.9)$ & $(1.3)$ & $(1.3)$ & $(2.4)$ & $(2.3)$ \\
\hline \multirow[t]{2}{*}{ Age $65 \&$ Coh. 38} & -3.0 & -2.8 & -0.9 & -0.8 & -3.7 & -3.5 \\
\hline & $(1.8)$ & $(1.8)$ & $(1.2)$ & $(1.2)$ & $(2.3)$ & $(2.2)$ \\
\hline \multirow[t]{2}{*}{ Age $61 \&$ Coh.39 } & -0.4 & -0.4 & -0.0 & 0.1 & -2.0 & -2.1 \\
\hline & $(1.7)$ & (1.7) & $(1.3)$ & $(1.3)$ & $(2.3)$ & $(2.3)$ \\
\hline \multirow[t]{2}{*}{ Age $62 \&$ Coh.39 } & -4.5 & -4.2 & -2.9 & -2.4 & -4.4 & -3.9 \\
\hline & $(1.7)^{* *}$ & $(1.7)^{*}$ & $(1.4)^{*}$ & $(1.3)$ & $(2.4)$ & $(2.3)$ \\
\hline \multirow[t]{2}{*}{ Age $63 \&$ Coh.39 } & -3.6 & -3.4 & -3.5 & -3.2 & -3.5 & -2.9 \\
\hline & $(1.8)^{*}$ & $(1.8)$ & $(1.4)^{*}$ & $(1.4)^{*}$ & $(2.5)$ & $(2.5)$ \\
\hline \multirow[t]{2}{*}{ Age $64 \&$ Coh.39 } & -1.0 & -1.5 & -1.2 & -1.5 & -2.9 & -3.5 \\
\hline & $(1.7)$ & $(1.7)$ & (1.4) & $(1.3)$ & $(2.4)$ & $(2.4)$ \\
\hline \multirow[t]{2}{*}{ Age $65 \&$ Coh.39 } & -1.3 & -1.6 & -1.4 & -1.6 & -1.1 & -1.7 \\
\hline & $(1.6)$ & $(1.6)$ & $(1.3)$ & $(1.3)$ & $(2.2)$ & $(2.2)$ \\
\hline \multirow[t]{2}{*}{ Age $61 \&$ Coh.40 } & -3.0 & -2.4 & -1.6 & -1.0 & -2.6 & -2.3 \\
\hline & $(1.9)$ & $(1.9)$ & $(1.5)$ & $(1.5)$ & $(2.5)$ & $(2.4)$ \\
\hline \multirow[t]{2}{*}{ Age $62 \&$ Coh.40 } & -8.4 & -8.0 & -5.4 & -4.9 & -6.3 & -6.0 \\
\hline & $(2.0)^{* *}$ & $(2.0)^{* *}$ & $(1.5)^{* *}$ & $(1.5)^{* *}$ & $(2.5)^{*}$ & $(2.4)^{*}$ \\
\hline \multirow[t]{2}{*}{ Age $63 \&$ Coh. 40} & -5.6 & -5.2 & -4.2 & -3.8 & -7.6 & -6.8 \\
\hline & $(2.1)^{* *}$ & $(2.1)^{*}$ & $(1.6)^{*}$ & $(1.6)^{*}$ & $(2.7)^{* *}$ & $(2.6)^{* *}$ \\
\hline \multirow[t]{2}{*}{ Age $64 \&$ Coh. 40} & -4.0 & -3.9 & -3.2 & -3.1 & -5.8 & -5.4 \\
\hline & $(2.1)$ & $(2.1)$ & $(1.6)^{*}$ & $(1.6)$ & $(2.7)^{*}$ & $(2.6)^{*}$ \\
\hline \multirow[t]{2}{*}{ Age $65 \&$ Coh.40 } & -5.7 & -5.1 & -3.8 & -3.3 & -3.8 & -3.5 \\
\hline & $(2.0)^{* *}$ & $(2.0)^{* *}$ & $(1.5)^{*}$ & $(1.5)^{*}$ & $(2.5)$ & $(2.5)$ \\
\hline Other $X \mathrm{~s}$ & no & yes & no & yes & no & yes \\
\hline Observations & 388378 & 388378 & 371779 & 371779 & 74277 & 74277 \\
\hline R-squared & 0.53 & 0.54 & 0.53 & 0.54 & 0.52 & 0.54 \\
\hline
\end{tabular}

NOTE.- Standard errors clustered by individuals in parentheses, ${ }^{*}$ significant at 5 percent, ${ }^{* *}$ significant at 1 percent. Other $X$ s include marital status, education, race, total members of the household, and geographic region. 
Table 6: ESTIMATED AVERAGE RETIREMENT AGE (IN MONTHS) MINUS THE 1937 COHORT AVERAGE RETIREMENT AGE (FEMALE SAMPLE).

\begin{tabular}{|c|c|c|c|c|c|c|}
\hline \multirow{4}{*}{1928} & \multirow{2}{*}{\multicolumn{2}{|c|}{$\begin{array}{lr}(1) \quad(2) \\
\text { Sophisticated }\end{array}$}} & (3) & $(4)$ & $(5)$ & (6) \\
\hline & & & \multicolumn{2}{|c|}{ Naive } & \multicolumn{2}{|c|}{ Restricted } \\
\hline & 2.05 & 1.61 & 1.88 & 1.40 & 1.17 & 0.61 \\
\hline & $(0.39) * *$ & $(0.38) * *$ & $(0.35) * *$ & $(0.34) * *$ & $(0.59) *$ & $(0.58)$ \\
\hline \multirow[t]{2}{*}{1929} & 1.31 & 0.87 & 1.77 & 1.25 & 1.98 & 1.30 \\
\hline & $(0.45) * *$ & $(0.44) *$ & $(0.35) * *$ & $(0.35) * *$ & $(0.59) * *$ & $(0.58) *$ \\
\hline \multirow[t]{2}{*}{1930} & 1.43 & 0.80 & 1.76 & 1.12 & 1.62 & 0.87 \\
\hline & $(0.45) * *$ & $(0.44)$ & $(0.35) * *$ & $(0.34) * *$ & $(0.60) * *$ & $(0.58)$ \\
\hline \multirow[t]{2}{*}{1931} & 0.99 & 0.58 & 1.33 & 0.87 & 1.25 & 0.50 \\
\hline & $(0.46)^{*}$ & $(0.45)$ & $(0.36) * *$ & $(0.35) * *$ & $(0.61)^{*}$ & $(0.60)$ \\
\hline \multirow[t]{2}{*}{1932} & 0.80 & 0.32 & 1.34 & 0.81 & 0.64 & 0.05 \\
\hline & $(0.46)$ & $(0.45)$ & $(0.36) * *$ & $(0.35)^{*}$ & $(0.62)$ & $(0.61)$ \\
\hline \multirow[t]{2}{*}{1933} & 1.21 & 0.94 & 1.45 & 1.10 & 1.12 & 0.76 \\
\hline & $(0.49) * *$ & $(0.48) *$ & $(0.38) * *$ & $(0.37) * *$ & $(0.64)$ & $(0.63)$ \\
\hline \multirow[t]{2}{*}{1934} & 0.72 & 0.37 & 1.08 & 0.69 & 0.26 & -0.10 \\
\hline & $(0.49)$ & $(0.48)$ & $(0.38) * *$ & $(0.37)$ & $(0.64)$ & $(0.63)$ \\
\hline \multirow[t]{2}{*}{1935} & -0.07 & -0.28 & 0.40 & 0.13 & -0.41 & -0.70 \\
\hline & $(0.48)$ & $(0.47)$ & $(0.38)$ & $(0.37)$ & $(0.65)$ & $(0.63)$ \\
\hline \multirow[t]{2}{*}{1936} & -0.40 & -0.57 & -0.02 & -0.23 & -0.01 & -0.34 \\
\hline & $(0.54)$ & $(0.52)$ & $(0.37)$ & $(0.36)$ & $(0.64)$ & $(0.62)$ \\
\hline \multirow[t]{2}{*}{1938} & -1.82 & -1.64 & -1.28 & -1.13 & -1.16 & -1.21 \\
\hline & $(0.52) * *$ & $(0.51) * *$ & $(0.35) * *$ & $(0.34) * *$ & $(0.63)$ & $(0.62)^{*}$ \\
\hline \multirow[t]{2}{*}{1939} & -1.98 & -1.58 & -1.69 & -1.32 & -2.75 & -2.51 \\
\hline & $(0.46) * *$ & $(0.44) * *$ & $(0.36) * *$ & $(0.35) * *$ & $(0.62) * *$ & $(0.61)^{* *}$ \\
\hline \multirow[t]{2}{*}{1940} & -2.34 & -1.91 & -1.75 & -1.39 & -3.27 & -2.85 \\
\hline & $(0.54) * *$ & $(0.53) * *$ & $(0.42) * *$ & $(0.41) * *$ & $(0.67) * *$ & $(0.66) * *$ \\
\hline Other $X \mathrm{~s}$ & no & yes & no & yes & no & yes \\
\hline
\end{tabular}

NOTE.- Sum of the coefficients (multiplied by 12/100) of a given cohort excluding age 61. Other $X$ s include marital status, education, race, total members of the household, and geographic region. Standard errors clustered by individuals in parentheses, ${ }^{*}$ significant at 5 percent, ${ }^{* *}$ significant at 1 percent. The values in squared brackets represent the change in the average retirement age divided by the change in the NRA. 
Table 7: ESTIMATED AVERAGE RETIREMENT AGE (IN MONTHS) MINUS THE 1937 COHORT AVERAGE RETIREMENT AGE (MALE SAMPLE).

\begin{tabular}{|c|c|c|c|c|c|c|}
\hline \multirow{3}{*}{$\begin{array}{l} \\
1928\end{array}$} & \multirow{2}{*}{\multicolumn{2}{|c|}{$\begin{array}{l}(1) \quad(2) \\
\text { Sophisticated }\end{array}$}} & \multirow{2}{*}{\multicolumn{2}{|c|}{ Naive ${ }^{(4)}$}} & \multicolumn{2}{|c|}{$(5) \quad(6)$} \\
\hline & & & & & \multicolumn{2}{|c|}{ Restricted } \\
\hline & $\begin{array}{c}0.82 \\
(0.43)\end{array}$ & $\begin{array}{c}0.26 \\
(0.42)\end{array}$ & $\begin{array}{c}0.86 \\
(0.39)\end{array}$ & $\begin{array}{c}0.44 \\
(0.38)\end{array}$ & $\begin{array}{c}0.30 \\
(0.65)\end{array}$ & $\begin{array}{l}-0.07 \\
(0.63)\end{array}$ \\
\hline \multirow[t]{2}{*}{1929} & 0.63 & 0.06 & 1.07 & 0.55 & 0.57 & 0.02 \\
\hline & $(0.49)$ & $(0.48)$ & $(0.39) * *$ & $(0.38)$ & $(0.66)$ & $(0.64)$ \\
\hline \multirow[t]{2}{*}{1930} & 0.41 & -0.01 & 1.20 & 0.80 & 0.68 & 0.39 \\
\hline & $(0.49)$ & $(0.48)$ & $(0.38) * *$ & $(0.37) *$ & $(0.66)$ & $(0.64)$ \\
\hline \multirow[t]{2}{*}{1931} & 0.89 & 0.52 & 1.41 & 1.08 & 0.83 & 0.61 \\
\hline & $(0.50)$ & $(0.49)$ & $(0.39) * *$ & $(0.38) * *$ & $(0.67)$ & $(0.65)$ \\
\hline \multirow[t]{2}{*}{1932} & 0.79 & 0.53 & 1.13 & 0.92 & 0.20 & 0.07 \\
\hline & $(0.51)$ & $(0.50)$ & $(0.40) * *$ & $(0.39) * *$ & $(0.68)$ & $(0.66)$ \\
\hline \multirow[t]{2}{*}{1933} & 0.08 & -0.15 & 0.74 & 0.53 & 1.31 & 1.20 \\
\hline & $(0.53)$ & $(0.52)$ & $(0.41)$ & $(0.40)$ & $(0.71)$ & $(0.69)$ \\
\hline \multirow[t]{2}{*}{1934} & 0.06 & -0.21 & 0.47 & 0.26 & 0.93 & 0.74 \\
\hline & $(0.54)$ & $(0.53)$ & $(0.42)$ & $(0.41)$ & $(0.70)$ & $(0.68)$ \\
\hline \multirow[t]{2}{*}{1935} & -0.37 & -0.52 & 0.17 & 0.05 & -0.43 & -0.49 \\
\hline & $(0.52)$ & $(0.50)$ & $(0.41)$ & $(0.40)$ & $(0.70)$ & $(0.67)$ \\
\hline \multirow[t]{2}{*}{1936} & -0.79 & -0.97 & -0.18 & -0.29 & 0.23 & 0.11 \\
\hline & $(0.57)$ & $(0.56)$ & (0.39) & $(0.38)$ & $(0.69)$ & $(0.67)$ \\
\hline \multirow[t]{2}{*}{1938} & -1.95 & -1.86 & -0.98 & -0.87 & -1.99 & -1.84 \\
\hline & $(0.56) * *$ & $(0.55) * *$ & $(0.38)$ ** & $(0.37) *$ & $(0.68) * *$ & $(0.66)$ ** \\
\hline \multirow[t]{2}{*}{1939} & -1.25 & -1.28 & -1.08 & -1.04 & -1.43 & -1.44 \\
\hline & $(0.49) * *$ & $(0.48) * *$ & $(0.39) * *$ & $(0.38) * *$ & $(0.67)^{*}$ & $(0.65) *$ \\
\hline \multirow[t]{2}{*}{1940} & -2.85 & -2.68 & -1.99 & -1.81 & -2.83 & -2.61 \\
\hline & $(0.57) * *$ & $(0.56) * *$ & $(0.44) * *$ & $(0.43) * *$ & $(0.71) * *$ & $(0.68) * *$ \\
\hline Other $X \mathrm{~s}$ & no & yes & no & yes & no & yes \\
\hline
\end{tabular}

NOTE.- Sum of the coefficients (multiplied by 12/100) of a given cohort excluding age 61. Other $X$ s include marital status, education, race, total members of the household and geographic region. Standard errors clustered by individuals in parentheses, ${ }^{*}$ significant at 5 percent, ${ }^{* *}$ significant at 1 percent. The values in squared brackets represent the change in the average retirement age divided by the change in the NRA. 
Table 8: ESTIMATED TREND IN THE AVERAGE RETIREMENT AGE (IN MONTHS).

\begin{tabular}{|c|c|c|c|c|c|c|}
\hline & $(1)$ & $(2)$ & $(3)$ & $(4)$ & $(5)$ & $(6)$ \\
\hline & \multicolumn{2}{|c|}{ Sophisticated } & \multicolumn{2}{|c|}{ Naive } & \multicolumn{2}{|c|}{ Restricted } \\
\hline & \multicolumn{6}{|c|}{ Panel A: Female Sample } \\
\hline \multirow[t]{2}{*}{$C: 1928-37$} & 0.11 & 0.02 & 0.23 & 0.12 & 0.12 & -0.01 \\
\hline & $(0.12)$ & $(0.12)$ & $(0.09) * *$ & $(0.09)$ & $(0.16)$ & $(0.15)$ \\
\hline \multirow[t]{2}{*}{$T: 1938-40$} & 1.20 & 1.02 & 0.90 & 0.75 & 1.21 & 1.14 \\
\hline & $(0.25) * *$ & $(0.25) * *$ & $(0.19) * *$ & $(0.18) * *$ & $(0.33) * *$ & $(0.32) * *$ \\
\hline \multirow[t]{3}{*}{$T-C$} & 1.08 & 1.00 & 0.67 & 0.63 & 1.09 & 1.15 \\
\hline & $(0.36) * *$ & $(0.35) * *$ & $(0.26) * *$ & $(0.25) * *$ & $(0.46) * *$ & $(0.45) * *$ \\
\hline & \multicolumn{6}{|c|}{ Panel B: Male Sample } \\
\hline \multirow[t]{2}{*}{$C: 1928-37$} & -0.05 & -0.12 & 0.12 & 0.06 & 0.11 & 0.06 \\
\hline & $(0.13)$ & $(0.12)$ & $(0.10)$ & $(0.09)$ & $(0.17)$ & $(0.16)$ \\
\hline \multirow[t]{2}{*}{$T: 1938-40$} & 1.17 & 1.13 & 0.73 & 0.66 & 1.21 & 1.14 \\
\hline & $(0.27) * *$ & $(0.26) * *$ & $(0.20) * *$ & $(0.20) * *$ & $(0.35) * *$ & $(0.34) * *$ \\
\hline \multirow[t]{2}{*}{$T-C$} & 1.22 & 1.25 & 0.61 & 0.60 & 1.10 & 1.08 \\
\hline & $(0.38) * *$ & $(0.37) * *$ & $(0.28) *$ & $(0.27) *$ & $(0.49) *$ & $(0.47)^{*}$ \\
\hline Other $X \mathrm{~s}$ & no & yes & no & yes & no & yes \\
\hline
\end{tabular}

NOTE.- Sum of the coefficients (multiplied 12/100) of a given cohort excluding age 61. Other Xs include marital status, education, race, total members of the household, and geographic region. Standard errors clustered by individuals in parentheses, ${ }^{*}$ significant at 5 percent, ${ }^{* *}$ significant at 1 percent. 